УДК 1683

ГРНТИз6

\title{
CRUSTAL DISPLACEMENT BASED ON THREE STAGES GEODETIC STUDIES RESULTS IN SPITAK GEODYNAMIC POLYGON
}

\section{Head of Geodesy and Mapping Department of State Committee of the Real Property Cadastre of the \\ Government of the Republic of Armenia \\ Margaryan Anush Ashotovna \\ National University of Architecture and Construction of Armenia \\ Tovmasyan Suren Vladimirovich \\ Head of the Real Property Cadastre of the Government of the Republic of Armenia \\ Harutyunyan Narine Vahanovna \\ National University of Architecture and Construction of Armenia \\ DOI: 10.31618/ESU.2413-9335.2020.2.75.832}

\section{ABSTRACT}

A network of dual-frequency global navigation satellite systems and digital levelling instruments has been established around Spitak, Armenia with the goal of recording changes to the Earth's crust near to this major earthquake zone. The study was initiated in response to the 1988 Armenian earthquake and is focused on the Sarighamish, Javakhet, Pambak-Sevan, Spitak and Akhuryan faults. Results demonstrate differential movement across fault zones that suggest monitoring of crustal change could be useful in the predicition of large earthquake events.

\section{АННОТАЦИЯ}

В зоне Спитакского землетрясения для проведения геодезического мониторинга с целью обнаружения деформаций земной коры были выполнены наблюдения с применением глобальных спутниковых систем и нивелирные работы I класса. Цикличные наблюдения были начаты после Спитакского землетрясения 1988 года на территории разломов Саригамиш, Джавахет, Памбак-Севан, Спитак и Ахурян. Исследования вдоль активных разломов демонстрируют дифференциальное движение земной коры и предполагают, что мониторинг изменений земной коры в сочетании с геологическим анализом может быть полезен при прогнозировании сильных землетрясений.

Key words: Geodynamic polygon, tectonic faults, the earth's crust dynamics, displacement, levelling.

Ключевые слова: геодинамический полигон, тектонические разломы, динамика земной коры, смещение, нивелирование.

\section{Introduction}

Armenia is located in the contact zone between the irection of 28+/-3 mm speed annually (Fig.1).
Arabian and Eurasian plates where the Arabic plate has been recorded with a movement in the north-western $d$

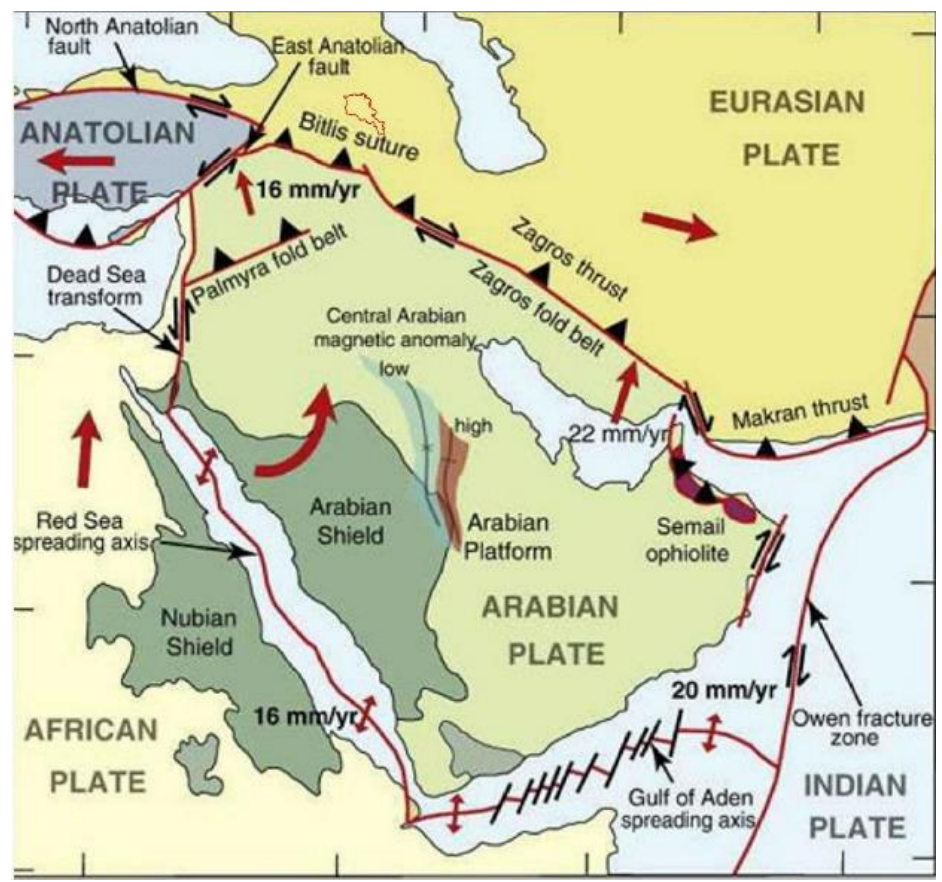

Figure 1 Movements of Eurasian and Arabian plates 
This movement results in continuous deformation of the Earth's crust within Armenia where a long history of earthquakes and related fault movement have been noted. The first high accuracy data that recorded this movement in Armenia and adjacent territories was made in 1997 jointly between National Seismic Defense Service (NSDS) of the Massachusetts Institute of Technology and the Institute of Geophysics of the Russian Academy of Sciences. [1]. On December 7, 1988 a magnitude 6.8 and a maximum MSK intensity of X (Devastating) earthquake occurred in the Spitak region of northern Armenia and caused widespread damage. The Spitak area contains a number of major faults including the Sarighamish, Javakhet, PambakSevan, Spitak and Akhuryan faults all of which have been historically active. Understanding the interplay between these is important for forecasting seismological risks and possible disasters in connection with it. In order to address the fault movements a network of dual-frequency global navigation satellite systems and digital levelling instruments was established around Spitak, Armenia with the particular vertical movements across faults, goal of recording changes to the Earth's crust, and in near to this major earthquake zone. Specifically, data was necessary to address questions about the extended width of the elastic tensions (deformation) in order to potentially issue forecasting of future earthquakes events.

\section{Background}

In formulation of his Elastic Rebound theory H. F. Reid clearly described the origin of earthquake mechanism and highlights the importance of geodetic surveying for the potential prediction of earthquake [2]. His work was based on the 1946, 6.3 magnitude California event which destroyed much of the city of San Francisco. During the earthquake, movement had occurred along a fault with up to $6 \mathrm{~m}$ vertical throw. After the earthquake, dual triangulation measurements were carried out around the earthquake epicenter zone and showed movements of the geodetic points that were not chaotic but regularly. Records showed that near to the fault the major displacement was recorded with exponential displacement away from the faults. Reid's theory can be used to explain how pressure slowly builds up over time along a fault line and then an earthquake releases this pressure rapidly and causes the crust to shift. In addition he noted that imitation point of earthquake vibrations could be tied to the point above which the fault started to break as recorded in the compression wave signatures, but that the first shear wave recorded was not coincident with this. This discrepancy and the associated crustal displacement led to the work of Beutler et al and the recognition of the potential in observations for prediction of impending earthquake [3].

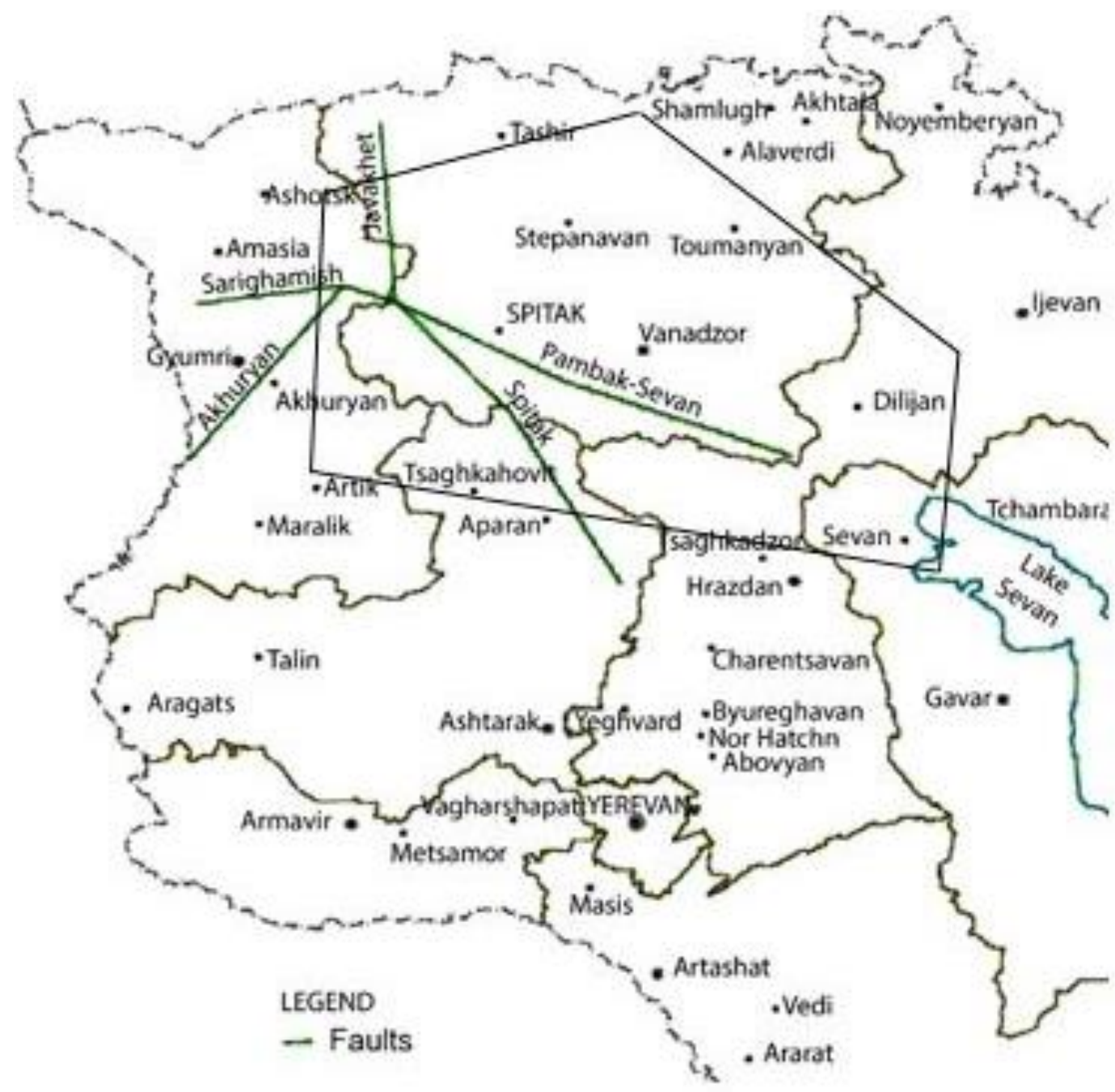

Figure 2 Geodynamic polygon and seismo-active faults of the Spitak region 


\section{Field Methodology}

In 2013 the Department of Geodetic Observation and Measurements of Geodesy and Cartography (SNCO) initiated a study in the Spitak area using a geodetic polygon with GNSS receivers based on previous work carried out by Manukyan et al [4]. To cover the Spitak area (Fig. 2). The network extends across the regions of
Lori, Shirak, Aragatsotn and Kotayk. 65 of the original installations exist today while 23 have been destroyed over that time. Specific locations are shown on figure 3 . Of the original, 52 benchmarks of I class (20 wall benchmarks, 20 ground benchmarks, 12 rock benchmarks) (Fig.3) were also established [4].

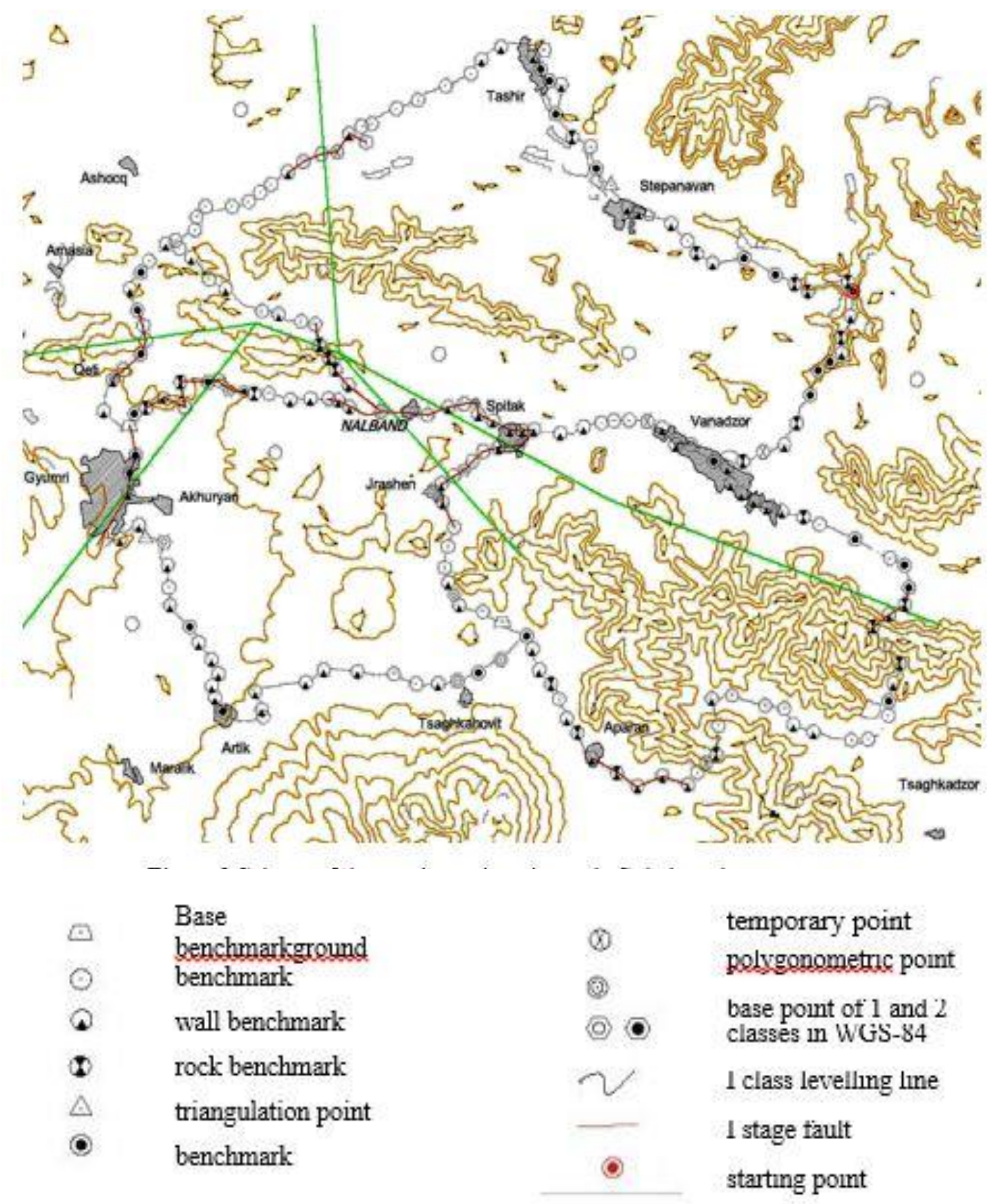

Figure 3 Schemeof the geodynamic polygon in Spitak region

New benchmarks have installed taking into account previous levelling line direction (without changing it) and their description was given. The wall benchmarks have installed on the breast walls of the building and concrete bridges, and center of rock benchmarks are 50 $\mathrm{cm}$ of underground (recognition sign is approximately in $1 \mathrm{~m}$ distance).
In the seismically active fault zones observation were carried out with 3 stages (1 stage in each year). In order to study earth crust vertical movements I class levelling (totally in $723.5 \mathrm{~km}$ of length) have been done by using NA-3003 modern digital leveling instruments and hatched invar yardsticks (I stage $267.7 \mathrm{~km}$, II stage $344.7 \mathrm{~km}$, III stage $111.1 \mathrm{~km}$ ). The first class levelling network is composed of six nod and ten lines, which 
forms four close polygon. The I class levelling carried out on the previous I and II lines and on the new created levelling line of Vardaxhbyur -Saralang (from ground benchmark 4302 to wall benchmark 1943). The levelling results have been recorded in summery papers. The balanced results were processed using Microsoft Excel and are shown on Fig. 4 and 5. In total 48 base points and benchmarks were observed in order to study the horizontal displacments in te World Geodetic System (In I, II and III stages 23 basepints and 25 benchmarks).

The results were balanced and coordinate points were calculated by LEICA GEO Office Combined 8.3 software package using both the reference stations of ARMPOS net created in 2013 and the RINEX station near the Spitak region. The ARMPOS net consists of 12 permanent geodetic reference stations, which includes previous 8 geodetic points ( 0 and I classes).

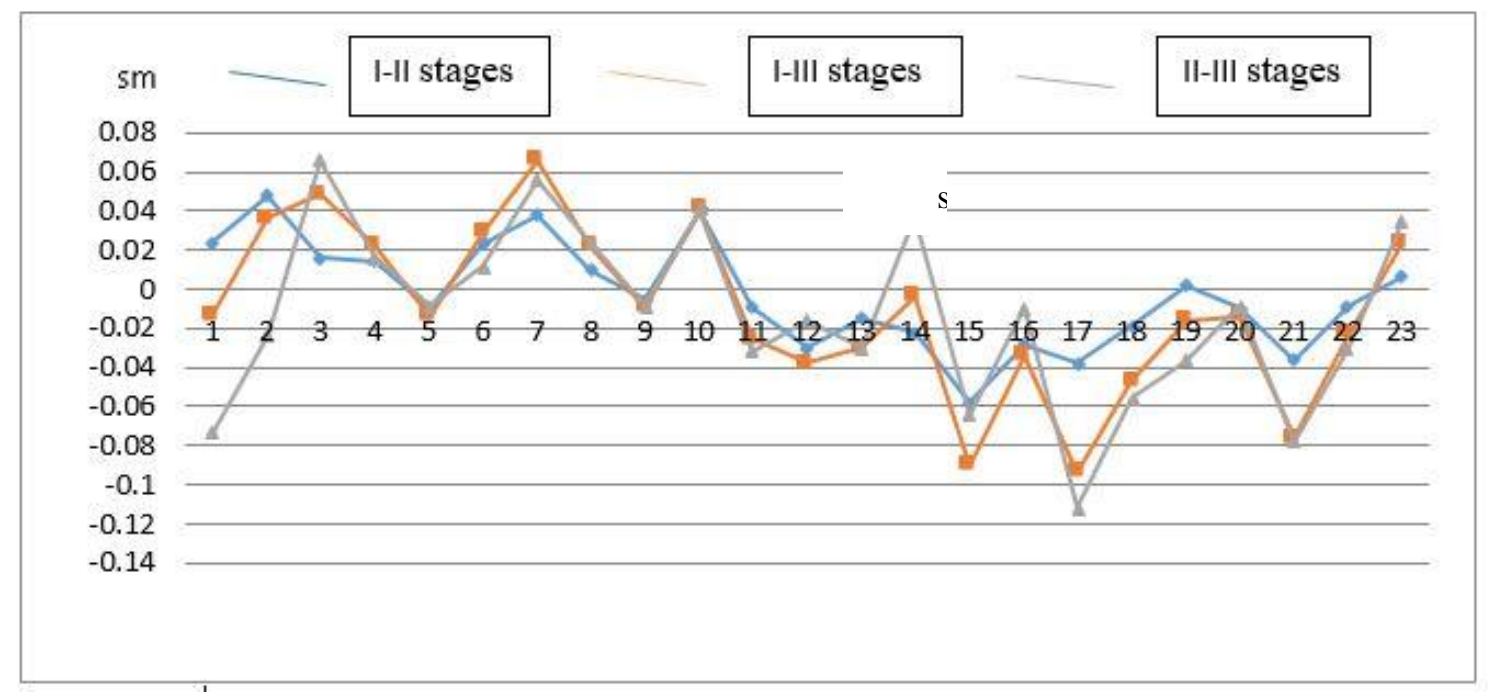

Figure 4. Earth crust vertical displacements on benchmarks

The coordinates of the permanent reference stations are in the ARMREF02 system, which is calculated in ITRF2008 the standard International Terrestrial Reference System. ARMREF02 is the official geodetic reference system of Armenia, which corresponds to the ITRS International Terrestrial Reference System and was created on base 2002.9 epochs (period) of ITRF2000.

After leveling observations performedin the geodynamic polygon, the leveling differences between monitor points including gravity stations were determined. Theprecisions for leveling differences were less than $+/-1 \mathrm{~mm} / \mathrm{sq} \mathrm{km}$.

The analysis of heights results of 23 GPS base points shows that the greatest positive vertical displacements are recorded on the base points of Norashen and Akhurian-8 (62 mm), Vardaxpyur-Small Sariar (59 mm) regions and negative displacements are recorded on the base points of Stepanavan - Vahagn gorge regions (-11 $\mathrm{mm})$.

The levelling measurements on 25 benchmarks shows that most positive vertical displacements were recorded on $7(+0.08)$ and $23(+0.06)$ benchmarks regions, and negative vertical displacements were recorded at 6 ($0.13 \mathrm{~mm})$ and $12(-0.09 \mathrm{~mm})$ benchmarks regions and on the 23 base points shows that most positive vertical displacements were recorded on $7(+0.07)$ and $3(+0.05)$ base points and negative displacements were $15(-0.08)$ and $7(-0.09)$ base points.

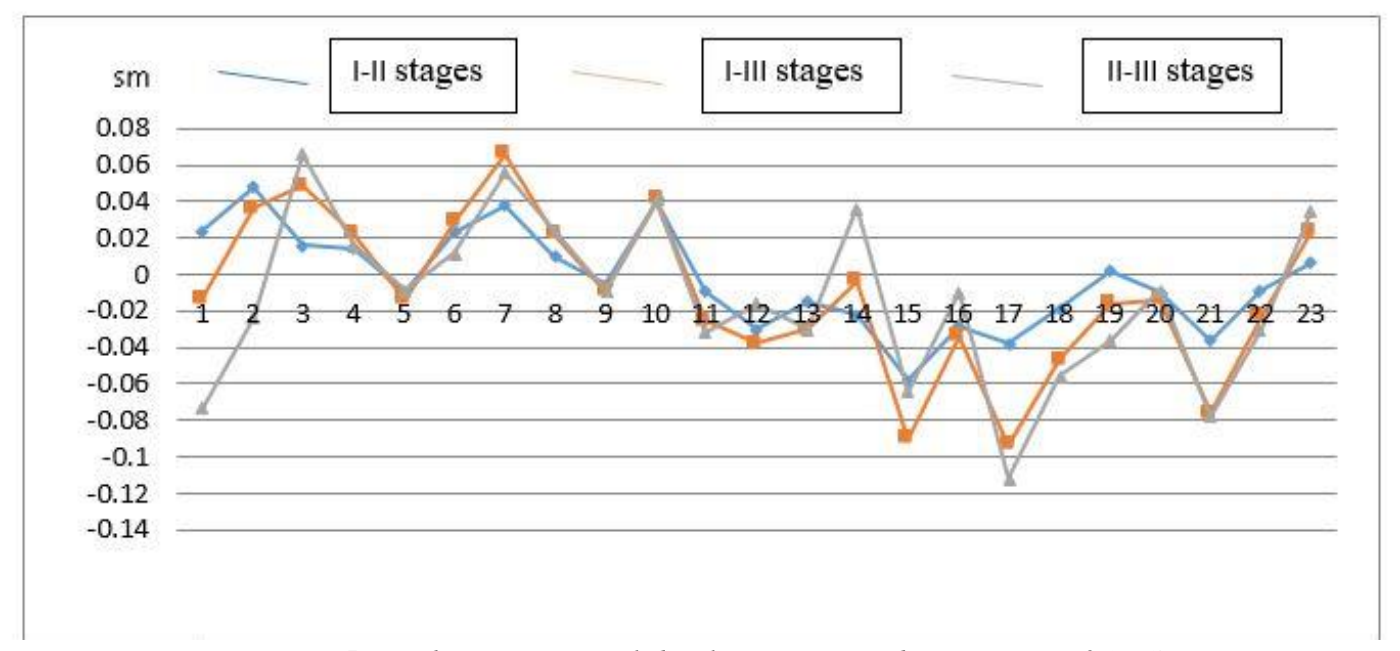

Figure 5.Earth crust vertical displacements on base points of GPS 
In I class levelling net includes 1 and 2 classes base points of WGS-84 ARMREF02, which absolute heights have been determined by GPS stations. Values of elevations obtained by two ways enabled to establish in 1977 a link between Baltic elevation system and elevations (normal and geodetic) determined by GPSs in WGS-84 ARMREF02 system. This makes it possible to obtain precise transition coefficients for RA area. I class benchmarks 408 are used as a basis for balancing I class-levelling net. Local X. Positioning System+ software is used for balancing the heights. Errors and permissible value for each section obtained after balancing. Before starting, I class leveling works, the accuracy of gravity measurements have been under controlled, for calculating the correction of normal heights system. The well-known Buge's formula is used in the calculation of normal heights system.

On the Earth's surface Gravity acceleration is calculated by the Bouguer's anomaly formula in the Potsdam system:

$$
g_{P Z}=\left(g_{P}-\gamma_{H}\right)+\gamma_{H}^{0}+0.0419 \delta H_{B Z}-0.3086 H_{B Z}
$$

Where, $\gamma_{H}^{0}$ - the acceleration of the gravity force on the surface of equipotential ellipsoid, $\delta=2.30 \mathrm{~g} / \mathrm{sm}^{3}$

$\delta=2.30 \mathrm{~g} / \mathrm{sm}^{3}$-the density of the intermediate layer, $H_{B z}-$ the normal height in Baltic system.

$$
\gamma_{H}^{0}=978030\left(1+0.005302 \sin ^{2} B-0.000007 \sin ^{2} 2 B\right)
$$

Gravity force acceleration of the $H_{B}$ height gravimetric point is corrected by the following formula:

$$
g_{P}=g_{P z}+d g
$$

If $H_{B Z}>H_{B}$, then

$$
\begin{gathered}
\Delta \gamma_{H}(h)=0.30855(1+0.00071 \cos 2 B) h-0.0723 h^{2} 10^{-6} \\
h=H_{B Z}-H_{B}
\end{gathered}
$$

If, $H_{B z}<H_{B}$, then

$$
d g=-\Delta \gamma_{H}(h)
$$

Where, $h=H_{B}-H_{B Z}$

In 2014 - 2016 Geophysics and Engineering Seismology Institute of National Academy of Sciences of RA carried out gravity measurements with an accuracy of $0.1 \mathrm{mGal}$ on 22 benchmarks. On benchmarks that have not been measured, the relative values of gravity acceleration $(\Delta \mathrm{g})$ have been obtained by method of interpolation. The results could be used for the adjustment quasi-geoids model of RA. It's satisfying accuracy allows to obtain heights values for topographic and surveying works without carrying out levelling. Which will bring savings of time and financial resources [5].

The analysis of three stages shows that observed and measured heights differences on regions of benchmarks and base points are the same (except height differences on the 2134 benchmark ( $-149 \mathrm{~mm}$ ) which may depends on balancing of levelling points).

After three stage observations, it was supposed that vertical crustal displacements occur in intensive speed on the Spitak earthquake center.

The use of satellite systems is of great importance when observing horizontal deformations of the earth's surface. Using satellite observations, it is easier to take measurements, but it is much more difficult and sometimes ambiguous to process the obtained data, which can lead to significant distortions in the final assessment of the current geodynamic state of the subsoil.

Technological features of geodetic surveys make it possible to more accurately measure the vertical component with the help of leveling, and the horizontal component with the help of satellite observations.
As a result of Spitak's geodynamic region observations, we conclude that when assessing the current changes in the Earth's crust, it is necessary not only to analyze the data obtained from various observations and measurements, but also to compare them with the data obtained as a result of the integrated implementation of new scientific ideas and technologies in various fields, including geophysics, studying geodynamic phenomena, seismology, tectonics, neotectonics, geology, stratigraphy, geomorphology, studying the relief of the earth's surface.

\section{References}

1. Larson, KP, Bodin, Gomberg, J 2003, 'Using 1 $\mathrm{Hz}$ GPS Data to Measure Deformations Caused by the Denali Fault Earthquake', Science, vol. 300, pp. 14211424.

2. Reid, HF. 1910, 'The Mechanics of the Earthquake', The California Earthquake of April 18, 1906, Report of the State Investigation Commission, Vol.2, Carnegie Institution of Washington, Washington, D.C.

3. Beutler, GL, Mueller,II, Neilan, R 1994,'The International GPS Service for geodynamics (IGS)', Bulletin. Géodésique, vol. 68, no. 1, pp. 39-70.

4. Manukyan, LV, Harutyunyan, NV, Lazarenko, NH 2016, 'Modeling of crustal displacement based on geodetic studies results in Spitak Geodynamic polygon'. Selected, peer reviewed papers from the $8^{\text {th }}$ International Conference on Contemporary Problems of Architecture and Construction, pp. 200-202, Yerevan

5. Bock, Y, Nikolaidis, RM, de Jonge, PJ,Bevis, M 2000,'Instantaneous geodetic positioning at medium distances with the Global Positioning System',Journal of Geophysical Research,vol. 105, pp. 28223-28253. 